\title{
Understanding Student Retention in Greece: The Impact of Socioeconomic Factors on Academic Success
}

\author{
Olga Tzafea \& Eleni Sianou \\ University of Ioannina, School of Philosophy \\ Department of Philosophy, Education and Psychology
}

Received 10 October 2018 • Revised 30 November 2018 • Accepted 10 December 2018

\begin{abstract}
This article focuses on the issue of retention in Greek higher education institutions. It is an issue of growing significance in the last decades, after the expansion of higher education and the increase in the number of university students. It is based on a literature review and the results of a research the aim of which was to investigate the factors to which students' attribute the fact that they have either not completed their studies in the period nominally expected for their study programme, or have withdrawn. Research data show that retention constitutes a complex social problem and that there is a relationship between retention and socioeconomic factors. We conclude that a full understanding of the issue, as well as efforts to increase student success presuppose the study of social parameters, which will examine the relationship between students' socioeconomic background and their studies, within each country's specific financial, social and cultural framework.
\end{abstract}

Keywords: retention, higher education, social class, drop out, academic success.

\section{Introduction}

In the last decades there has been a shift in research interest from access to higher education to participation and success in it, while issues such as retention, defined as "the extent to which learners remain within a higher education institution and progress to complete their study programme within a given time frame" (European Commission/EACEA/Eurydice, 2014: 29) have gained prominence. This shift is mainly due to the following factors. First, it is now generally recognized that retention is linked to social justice and that the expansion of higher education does not necessarily entailing equal opportunities. It is now widely recognized that participation in higher education should be accompanied by opportunities for success within it. Official data show that although access to higher education has expanded greatly in the last decades, completion rates (the proportion of students who start and complete their studies) have remained roughly the same (Tinto, 2012). A growing number of students either do not complete a programme of study in a pre-determined time-period or drop out. Research data show that on an international level one in four students drop out from their studies, while in Britain many higher education institutions have high drop out rates (HEFCE, 2006).

Retention and success in higher education for students from disadvantaged backgrounds are persistent issues for governments and policy makers through the world (Yorke \&

(C) Authors. Terms and conditions of Creative Commons Attribution 4.0 International (CC BY 4.0) apply. Correspondence: Olga Tzafea, Postdoctoral researcher, Department of Philosophy, Education and Psychology, University of Ioannina, P.O box 1186, Postcode 45110 Ioannina, GREECE. E-mail: olgatzaf@gmail.com. 
Thomas, 2003). Governments invest in higher education having adopted a "human capital" approach towards it, believing there are constructive associations between higher education, transition to the labour market and economic growth (Quinn, 2006; Shavit et al., 2007; SianouKyrgiou \& Tsiplakides, 2011). Apart from governments, these issues also occupy in a large extent higher education institutions. Due to their commitment to the students whom they enroll, high levels of attrition "raise questions about the fulfillment of that commitment" (Yorke \& Longden, 2004: 1). The repercussions of the problem lead institutions and those responsible for the planning of education policy to take measures aimed at increasing retention rates.

- Fifty percent (50\%) of students has father in partly-skilled occupations.

- Sixty percent (60\%) of students have father who has reached secondary education level.

- Seventy percent (70\%) of students come from urban areas.

- Students from lower socioeconomic background were not well informed before they enter university about the academic life, they lack preparation for decision-making, they didn't meet academic demands and that they didn't develop academic expectations.

- Social class is closely related to retention.

On the basis of the above discussion, the aim of this article is to investigate the factors to which students attribute the fact that they have either dropped out or have not completed their studies in the period nominally expected for their study programme. To achieve this aim, the article is organized as follows. In the next part we present the explanatory frameworks put forward for the examination of retention and attrition. This is followed by a brief description of the situation in Greece and a description of the research methodology. We then present the research findings and the conclusions drawn from the discussion of the findings.

\subsection{Explanatory frameworks}

The issue of student retention has attracted much research interest and effort is made to make recommendations in order to increase student success and completion rates. A number of different approaches have been proposed, and the relevant literature draws mainly from the disciples of sociology and psychology (Yorke \& Longden, 2004). Many studies investigate the issue of retention and attrition from a psychological perspective placing emphasis on students' personal qualities and characteristics (Bean \& Eaton, 2000). More recently, a growing number of studies attempt to investigate the issue based on sociological theories kal explanatory frameworks. The most commonly used frameworks that draw inspiration from sociology are that of Tinto (1975, 1987, 1988, 1993) and Bourdieu's theory of cultural reproduction (Bourdieu \& Passeron, 1979; Bourdieu, 1986).

According to Tinto, there is a relationship between retention and students' academic and social engagement (Tinto, 2012). He argues that "the greater students' involvement in the life of the college, especially its academic life, the greater their acquisition of knowledge and development of skills" (Tinto 1997: 600). In this framework, the main reason for non-completion is the fact that students do not manage to "integrate into the institution, academically and/or socially" (Yorke \& Longden, 2004: 78). The lack of academic and social integration has detrimental effects to completion of a programme of study and leads students to the decision to leave early. It is important to note that in Tinto's work, social and academic integration are considered as separate concepts who are, at the same time, interrelated. This means that the lack of either social or academic integration is not enough for university success, when there is a noticeable deficit in the other.

Studies based on Tinto's theoretical framework, mention three factors that impact on retention and drop out: students' incompatibility with the programme of study, financial 
difficulties and poor experiences from student life (Thomas, Adams \& Birchenough, 1996; Yorke, 1999). Other studies mention factors such as students' academic background, academic and social integration, attitude towards studies, motivation and compatibility between students and the higher education institution (Moller-Wong \& Eide, 1997).

In the framework of Bourdieu's theory of social reproduction, the concept of "cultural capital" is a useful tool in understanding academic trajectories, especially as regards the comparison between the students' and the universities culture (Bourdieu, 1986). Cultural capital, which can be transformed into financial capital, determines the degree of student integration in the university's culture and academic life. Students from families with a high level of financial and social capital with parents who have participated in higher education are usually integrated easier and faster in the academic environment. They are, thus, more likely to complete their studies in the predetermined time period. Their social capital helps them decode faster the norms and the requirements of the university as a social framework, which allows them to have higher achievement levels and makes it easier for them to deal with potential academic difficulties and problems.

Contemporary studies suggest that retention is a multifaceted issue and that it cannot be examined and explained in an easy, linear fashion (Harper \& Quaye, 2009). Research has shown that social parameters play an important role, since there is a relationship between social class and academic trajectories from the first year to higher education to graduation. The family's financial and cultural capital determines preparation, student life, the cultivation of the relationship with knowledge, factors which result in inequalities as regards academic trajectories. Students with parents who have not participated in higher education are more prone to prolong their studies or drop-out, because they lack knowledge of the academic environment and familiarity with academic traditions and behavior patterns (Astin, 1993). They delay to develop expectations for their studies in relation to students who possess the necessary knowledge from their parents (Hossler et al., 1998).

Other parameters related to retention are the social and friendly circle of the students (Pascarella \& Terenzini, 2005), as expectations regarding successful completion of studies are associated with social interactions with their peers (Hossler et al., 1998). In addition, there is a relationship between retention and the extent to which students interact socially with other students and academic staff (Astin et al., 1987; Tinto, 1997). Finally, many studies have established a link between retention and students' performance in the lower educational levels and especially in secondary education (Tross et al., 2000), which is, in turn, greatly influenced by social class. Students with higher performance in secondary education are more likely not only to participate in higher education, but succeed within it.

In a similar vein, many studies conclude that socioeconomic factors differentiate academic trajectories and university success. For example, they are related to financial barriers in study completion, especially in higher education institutions with fees, which brings to the surface the importance of family income in academic success. Students from families with a low income have fewer possibilities to participate in higher education and complete their studies within the specified time-period (Adelman, 2006). Financial difficulties contribute to delay, since most of the students work in order to cover the cost of their studies (Ozga \& Sukhnandan, 1997).

\subsection{Student retention in Greece}

In Greece entrance to higher education institutions is based on the results obtained in the national exams at the end of upper-secondary education, while there are no fees for higher education. The number of students admitted is determined by the Ministry of National Education and Religious Affairs (numerous clauses). The limited number of places available in high-status 
university departments (e.g. Law or Medical School), coupled with the high demand for these departments has led to strong competition in the higher education entrance examinations. As a result, most upper-secondary school pupils receive out of school support (e.g. private tutoring) to be prepared for the exams and ensure admission to higher education. Less or no preparation decreases the opportunity to gain access on a department that is in high demand (Stamelos \& Kavasakalis, 2011). This privatisation of education makes the Greek educational system a highly selective one (Sianou-Kyrgiou, 2006).

Taking this into account, many students enter higher education without having succeeded on the desirable department. Under those circumstances, the problem of student retention in Greece seems to be greater in relation to other European countries. Official data show that for every ten "active" students in higher education institutions there is an equal number of students who have not completed their studies, and, thus, about $51 \%$ of all university students are characterized as "non-active" students. There is a large percentage of students who have either not completed their studies in the pre-determined time-period and are still studying or have dropped out (ELIAMEP, 2006). According to the Annual Report of Quality Assurance and Certification Authority of Higher Education (ADPI) (2015: 13), the graduation rate in Greece is ten percentage points below the average graduation rates of UNESCO countries in 2014.

Despite the urgency of the issue, however, research on student retention in Greek higher education institutions is very limited. The few studies that have been conducted show that students who are more prone to attrition or drop out are those studying in university departments which are dominated by lower social class students. Drop out rates are lower in higher status university departments which are dominated by students from more privileged social classes, such as the Medical or Law School (Stamelos, 2002).

It has also been argued that attrition is attributed to the reduction of the exchange value of university degrees in the labour market. As it has been argued "for the first time in Greek history there is a trend to disconnect university qualification from the labour market as a great percentage of university graduates does not find a job soon. This trend together with the substantial increase in the number of university students increase the tendency for noncompletion and dropping out, especially for specific university departments and population categories (Kiprianos \& Koniordos, 2003).

In general, in Greece research usually focuses on access to higher education rather than participation and success within it. Thus, researchers are now focusing on student retention in an attempt to examine social parameters, to find the underlying causes and make suggestions to deal with the problem. In this framework, the research data presented in this paper form part of a greater research study which was conducted in the University of Ioannina, a peripheral university in Greece.

\section{Research methodology}

The research was carried out, employing both quantitative and qualitative methods of data collection. More specifically, questionnaires were answered by a number of 766 students $(\mathrm{N}=766)$ who had not graduated from the University of Ioannina two years after the predetermined time-period for their program of study and had started their studies after the academic year 1999-2000. In addition, 30 semi-structured interviews were conducted. The triangulation of collecting data (Gohen \& Manion, 2002) helped us to better explain and analyze the research questions. Students personal information were obtained by the university register, which provided us with the relevant information, including telephone number and email address. It is a part of a larger research conducted in the University of Ioannina for the students who don't complete their studies in the normal period of time. University of Ioannina was established in 1964. It includes 
22 academic departments which count 13,500 undergraduate students.

According to this data, the students who had not graduated from the University of Ioannina two years after the pre-determined time-period for their program of study and had started their studies after the academic year 1999-2000 were 2,921. From which 766, that is, $\mathbf{2 8 . 3 \%}$, participated in the study. The composition of the sample by university department is shown in Table 1. After completing the quantitative research, we analyzed the questionnaires data using the program SPSS. Then, after we made a careful choice of the most important student-cases for our topic, for example, students in high risk of no completing their studies or withdraw, we conducted the qualitative research. In other words, we had 30 in-depth semi-structured interviews with students in high risk of dropping out. Students in a high risk of dropping out are thought to be those students whose age and social characteristics are, in a general literature view, included to non-traditional students.

The characteristics of the whole sample, according to the study department are shown on the Table 1. According to the gender characteristics, the majority of students were girls (55.8\%). As for their age, $88.6 \%$ were between $26-29$ years old. A small percentage (11.4\%) had undergone 30 years old.

Table 1. Percentage of students who participated in the study by university department

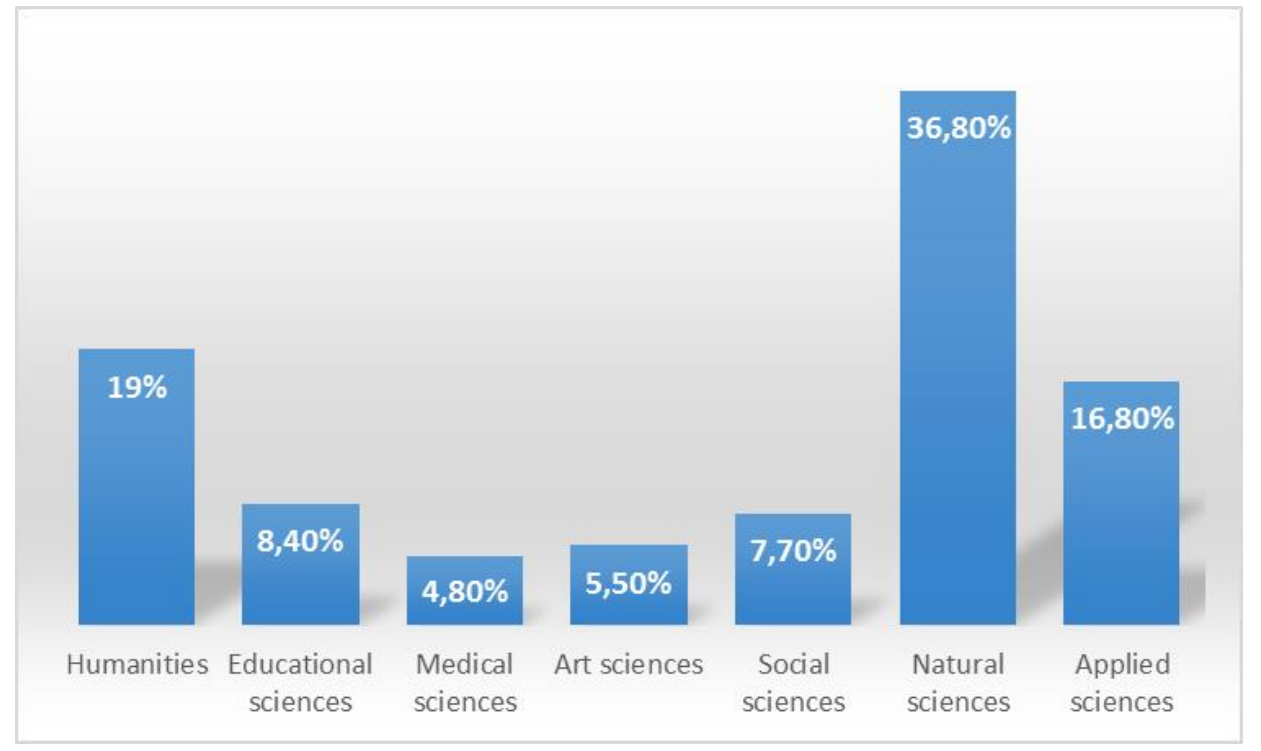

The variables we use to measure the socioeconomic characteristics of students are (a) father profession, (b) father's educational level, and (c) place of residence. Father's profession is measured according to the following categories: I=Professional occupations, II=Managerial and technical occupations, IIIa=Skilled non-manual occupations, IIIb=Skilled manual occupations, IV=Partly-skilled occupations (CASMIN Educational classification). Father's educational level was measured according to National Statistics Socio-economic Classification (NS-SEC) in the three following educational categories: (a) secondary education, (b) high education and postgraduate studies. Place of residence was measured according to the place that students live permanently, (a) in a big city center, (b) in a small city, and (c) in a small urban area. The reason we didn't measure mother's profession and educational level has only to do with the limitations of the article size and with the notion that we didn't expect to observe many differences between fathers and mothers socioeconomic background.

With this in mind, the research questions were:

(a) What are the demographic and social characteristics of the students who have not 
completed their studies in the period nominally expected for their study program or have withdrawn;

(b) What are the reasons to which they have either not completed their studies in the period nominally expected for their study program, or have withdrawn.

Our hypothesis is that students who are more likely to drop out or not complete their studies in the period nominally expected usually come from lower socioeconomic background and they reasons for that are associated with their cultural capital.

\section{Research findings}

\subsection{Demographic and social characteristics}

In answer to the first research question, we present the data collected concerning the demographic and social characteristics of the students who have not completed their studies in the period nominally expected for their study program or have withdrawn.

\section{Retention and father's occupation}

The statistical analysis of the research data provides strong evidence that the majority of students who have not completed their studies in the pre-determined time-period come mostly from families with low social and financial backgrounds, as shown in Figure 1. Similar studies conducted in other countries have shown similar findings (Pascarella \& Terenzini, 2005).

Figure 1. Distribution of students who have not completed their studies in the pre-determined time-period according to father's occupation (percentage)

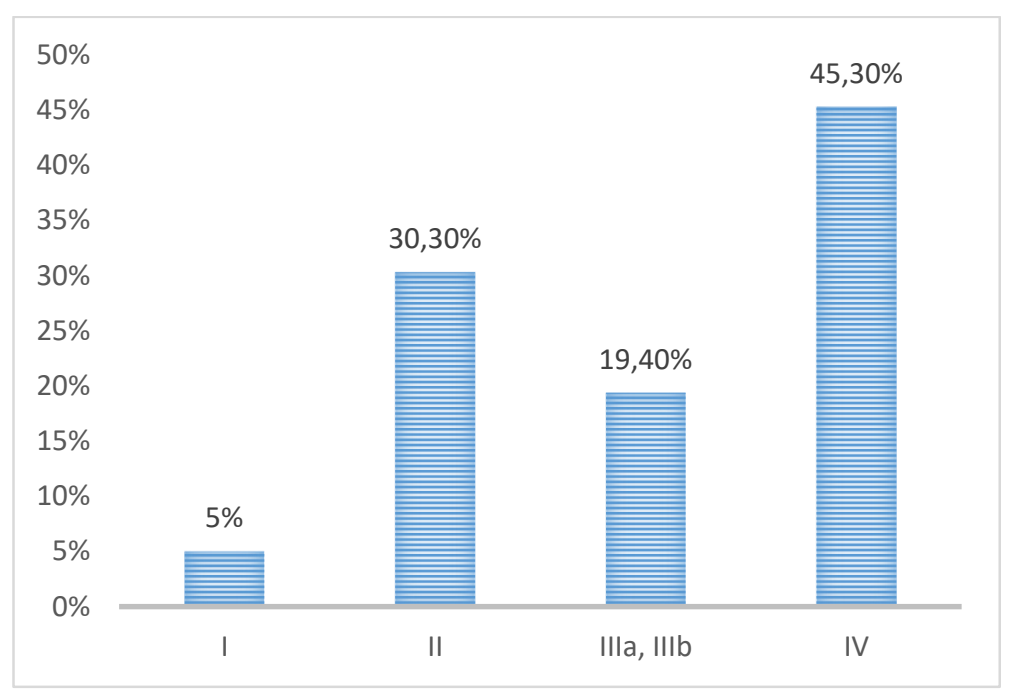

According to the table, it is interesting to note that only $5 \%$ of the students have father from the highest occupational categories. In addition, research data show that $45.3 \%$ of the students who have not completed their studies in the pre-determined time-period come from low family occupational background.

\section{Retention and father's education level}

In order to explore the relationship between social class and retention, we also collected data as regards father's education level. The research data are presented in Figure 2. 
Figure 2. Students who have not completed their studies in the pre-determined time-period according to father's education level (percentage)

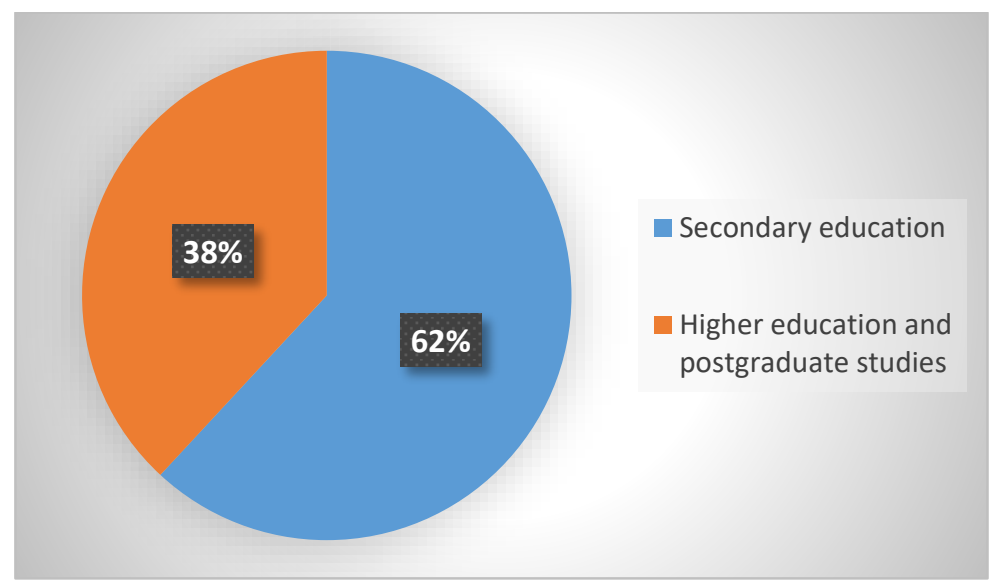

On the basis of the above data, we conclude that most students who did not complete their studies in the pre-determined time-period have a father with a lower education level. Data show that $61.9 \%$ of those who did not complete their studies in the pre-determined time-period have a father who is a compulsory education graduate, while only $36.2 \%$ have a father who is a university graduate.

\section{Retention and place of residence}

Research data reveal that place of residence is also associated to retention. The greatest percentage of students who did not complete their studies in the pre-determined timeperiod (70.4\%) come from a provincial city, $14.5 \%$ from a small town or village, while only $15 \%$ live in Athens, the capital. These data show that geographical inequalities exist, since students from agricultural areas are more likely to have lower retention rates compared to students from urban areas (Martin et al., 2001).

In the next part of the study we present the findings related to the second research question. In other words, the students' beliefs about the factors to which they attribute the fact that they did not complete their studies in the pre-determined time-period are presented and analysed.

\subsection{Interview analysis}

Above all, the analysis of qualitative data were collected by 30 semi-structured indepth interviews with students that were in a high risk to drop out, shows that students attribute failure to complete a study program in a pre-determined time-period because of a number of factors related to social class.

More specifically, the majority of students, $89.9 \%$, attributed the fact that they did not complete a programme of study in a pre-determined time-period to their low educational background. They argue that the knowledge gained from secondary education was not sufficient, and as a result they could not meet the academic demands. This was a factor mentioned most often by students from working class backgrounds. This is evidenced by the remarks of a female working class student who mentions: 
"My parents didn't care about in which department I'd study. I wanted to study to feel free and have the experience of student life. So I filled in the forms almost by chance, after taking into consideration only my grades and the grades needed for university entrance. When the course started I realized that I didn't have the necessary knowledge to attend the course, so I almost dropped out".

Another reason concerns higher education attribute attrition has to do with the issue of low decision-making. A large percentage of students (73.7\%) studied in a department that they didn't like to, was not one of the first choices but because of their performance in the national university entrance examinations. As has already been mentioned, students' admission to a department of a higher education institution is dependent on the grades they have been awarded in the national exams for university entrance, their preference for the different departments (as shown in the application they submit), and of the number of available places existing in each department (Kyriazis \& Asderaki, 2008).

For example, a student from lower middle class background mentioned:

"I chose the university department on the basis of my [secondary education] professors' judgment and university entrance exams, because I wanted to study at a department that would offer employment. My parents were neutral in relation to this. They had instilled to me the idea that I had to enter university and that after that all would be ok, but they didn't interfere about which department to choose. So I made my choice on the basis of occupational trajectories, but my choice wasn't correct".

Apart from the influence of the admission procedures, it is also interesting to note that 61.5\% of the students attribute the fact that they did not complete their studies in the predetermined time-period to the fact they could not meet the academic demands. They did not attend classes and preferred to enjoy university life, especially during the first year. They relate this tendency to the pressure they suffered preparing for the university entrance examinations, which in Greece also entails long hours dedicated to out-of-school support. This factor was more frequently mentioned by students from lower socioeconomic backgrounds. Students with parents who had studied at university were far less likely to mention this factor compared to students with parents who had no experience of higher education. As a student from the Department of Mathematics with parents who are secondary education graduates mentions:

"From the moment I entered university I felt free. Even if my performance in the first year was good, then I was influenced by the "sweet life". I lived my lost teenage years at university. I started to work. I didn't work to earn money, but because of the pressure I felt while at secondary education. I realized my mistake, but got carried away".

Expectations disappointment is another important factor, since it was mentioned by $74 \%$ of the students. It is related to the returns of the university degree for earning a high qualified job in the labour market. Research findings provide evidence that socioeconomic background determines students' expectations. For example, one student from the Department of Computer Science and Engineering dramatically expressed her feelings:

"I didn't graduate within the pre-determined time-period because the crisis made me lose my motivation for my studies. No one was praising me for my effort to graduate. Dead ends everywhere. Why should I study if the degree has no value? I expect nothing from my studies, I'll simply try to graduate so as not to feel I wasted all those years".

Research data show that students from lower socioeconomic backgrounds don't raise expectations. They believe that their study programmes at university do not provide them with the skills necessary for the labour market. This is exemplified by a student from the Department of Computer Science and Engineering who expresses doubts about the usefulness of his programme 
in the transition to the labour market:

"I study at the department of computer science and in all these years they haven't opened a computer to tell us 'this is a processor'. The courses have no practical value, they are highly theoretical and are useless in the labour market. And while we do not get skills, the professors' demands are extremely high. If one wants to graduate within the specific time-period they should face the situation as if attending upper secondary school, studying long hours, and going out only on Friday" (Student from the Department of Computer Science and Engineering).

Other factors were also mentioned by the participants. $64.2 \%$ of students mentioned that an important reason was the fact that their professors did not seem to evaluate positively their efforts, while $56.2 \%$ expressed the view that the program of studies was not well organized. It is also worth noting that $87.3 \%$ of the participants mentioned that they were not able to engage to the academic environment.

However, before presenting the conclusions of the study, it is important to acknowledge a limitation. It refers to the fact that a study which explores the reasons for students' withdrawal from higher education "risks various kinds of bias, including non-response, selfjustification, misattribution of cause, selective memory, distortion due to the passage of time, and so on" (Yorke \& Longden, 2004: 104). Consequently, generalizations are risky and may be addressed misleading outcomes.

\section{Conclusion}

Retention and success in higher education constitute a central theme in sociological research in recent years. Despite policies adopted in many countries aiming at widening participation in higher education, social inequalities remain (Raftery \& Hout, 1993). It has been argued that the expansion has often been accompanied by qualitative differentiation and stratification within higher education (Morley \& Aynsley, 2007; Sianou-Kyrgiou \& Tsiplakides, 2011). In general, this study shows that widening access to higher education has not provoked equal chances within it (Sianou-Kyrgiou, 2008), and that the issue of retention and success in higher education should be given priority.

As regards to the first research question about the demographic and social characteristics of the students who have not completed their studies in the period nominally expected for their study program or have withdrawn, the study shows that fifty percent of students has father in partly-skilled occupations, sixty percent of them have father who has reached secondary education level and seventy percent of them come from urban areas.

As regard to the second research question about the reasons to which they have either not completed their studies in the period nominally expected for their study program, or have withdrawn, the study shows that the majority of students who come from lower socioeconomic background expressed the following reasons: they were not well informed before they enter university about the academic life, they lack preparation for decision-making, they didn't meet academic demands and that they didn't develop academic expectations. On the basis of the research data presented above, it can be argued that there are many reasons why students leave their studies, and the boundaries between these reasons are not necessarily clear-cut. However, in accordance with studies conducted in the European Union countries, a major finding is that social class is of paramount importance, as "coming from a poor socio-economic background is the most significant factor leading a student to drop-out" (Quinn, 2013: 9). More specifically, research data reveal that social class is closely related to retention, since there is a relationship between the students' cultural capital and retention and success at university. Bourdieu's cultural capital theory constitutes a useful tool in understanding this relationship, the impact of financial, cultural 
and social capital in participation and the difficult position of students from less privileged social classes, even if they have overcome the difficulties by entering higher education.

This, in turn, means that social inequalities as regards success in higher education and transition to the labour market are maintained (Sianou-Kyrgiou, 2006, 2010). On the basis of the above discussion, it can be argued that the expansion of higher education may offer more opportunities in relation to access, but social inequalities remain, since the factors that lie behind students' decisions to drop out are closely linked to social class.

The research findings presented in this article are of significance for higher education research and policy which seeks to implement an institutionalised quality assurance system (Stamelos \& Kavasakalis, 2011). Any attempts to understand and deal with the issue of retention require (a) holistic approach to retention, acknowledging and addressing all factors impaction on retention (Quinn, 2013), and (b) a sociological perspective that examines the linkage between social class and educational success. In the same vein, measures aimed at reducing dropping out need to take into account the wider socioeconomic and cultural inequalities, as well as the broader structural, educational and societal characteristics in a country.

This research did not receive any specific grant from funding agencies in the public, commercial, or not-for-profit sectors.

\section{References}

Astin, A. (1993). What matters in college: Four critical years revisited. San Francisco: Jossey-Bass.

Astin, A. W., Korn, W., \& Green, K. (1987). Retaining and satisfying students. Educational Record, 68(1), 36-42.

Bourdieu, P., \& Passeron, J. C. (1977). Reproduction in education, society and culture. London: Sage.

Bourdieu, P., \& Passeron, J. C. (1979). The inheritors: French students and their relation to culture. London: Chicago University Press

Bourdieu, P. 1986. Distinction. London: Routledge.

Cohen, L., Manion, L., \& Morrison, K. (2002). Research methods in education. Routledge.

ELIAMEP, Hellenic Foundation for European and Foreign Policy (2006). Higher education in Greece in the new European and international context. Athens. (in Greek)

European Commission/EACEA/Eurydice (2014). Modernisation of higher education in Europe: Access, Retention and Employability 2014. Eurydice Report. Luxembourg: Publications Office of the European Union.

HEFCE (2006). Widening participation: a review. Report to the Minister of State for Higher Education and Lifelong Learning by the Higher Education Funding Council for England. Bristol: HEFCE.

Hossler, D., Schmit, J., \& Vesper, N. (1998). Going to college: How social, economic, and educational factors influence the decisions students make. Baltimore: Johns Hopkins University Press.

Kiprianos, P., \& Koniordos, M. (2003). The demystification of University: eternal students and study drop out. Contemporary Education, (132), 23-34. (in Greek)

Kyriazis, A., \& F. Asderaki (2008). Higher education in Greece. Bucharest: UNESCOCEPES, Monographs on Higher Education: European Centre for Higher Education. 
Martin, Y. M., Maclachlan, M., \& Karmel, T. (2001). Undergraduate completion rates: An update, Occasional Paper Series 01-F: Higher Education Division.

Moller-Wong, C. \& Eide, A. (1997). An engineering student retention study. Journal of Engineering Education, 86(1), 7-15.

Morley, L., \& Aynsley, S. (2007). Employers, quality and standards in higher education: Shared values and vocabularies or elitism and inequalities? Higher Education Quarterly, 61(3), 229-249.

Naidoo, R. (2003). Repositioning higher education as a global commodity: Opportunities and challenges for future sociology of education work. British Journal of Sociology of Education, 24(2), 249-259.

Ozga, J., \& Sukhnandan, L. (1997). Undergraduate non-completion in higher education in England. Report 2. Bristol: HEFCE

Pascarella, E. T., \& Terenzini, P. T. (2005). How college affects students (vol. 2). San Francisco: Jossey Bass.

Pugsley, L. (2004). The university challenge. Aldershot: Ashgate.

Quinn, J. (2013). Drop-out and completion in higher education in Europe among students from underrepresented group. An independent report authored for the European Commission. NESET: European Commission.

Raftery, A.E., and M. Hout (1993). Maximally maintained inequality: Expansion, reform, and opportunity in Irish education, 1921-75. Sociology of Education, 66(1), 41-62.

Shavit, Y., R. Arum, A. Gamoran, \& G. Menachem. (2007). Stratification in higher education: A comparative study. Palo Alto, CA: Stanford University Press.

Sianou-Kyrgiou, E., \& Tsiplakides, I. (2011). Similar performance, but different choices: Social class and access to higher education in Greece. Studies in Higher Education, 36(1), 89-102.

Sianou-Kyrgiou, E. (2010). From university to the labour market: Aspects of social inequalities. Athens: Metaixmio. (in Greek)

Sianou-Kyrgiou, E. (2006). Education and social inequalities: The transition from secondary to higher education (1997-2004). Athens: Metaixmio. (in Greek)

Stamelos, G. (2002). The Greek educational system. First and second level. Structures and quantitative data. Athens. KEE. (in Greek)

Stamelos, G., \& Kavasakalis, A. (2011). The public debate on a quality assurance system for Greek universities. Quality in Higher Education, 17(3), 353-368.

Tinto, V. (1975). Dropout from higher education: A theoretical synthesis of recent research. Review of Educational Research, 45(1), 89-125.

Tinto, V. (1987). Leaving college: Rethinking the causes and cures of student attrition. Chicago: University of Chicago Press.

Tinto, V. (1988). Stages of student departure. Journal of Higher Education, 59(4), 438-455.

Tinto, V. (1993). Leaving college: Rethinking the causes and cures of student attrition. $\Delta \varepsilon \dot{\tau \varepsilon \rho \eta ~ ' Е к \delta о o \eta . ~}$ Chicago: University of Chicago Press.

Tinto, V. (1997). Classrooms as communities: Exploring the educational character of student persistence. Journal of Higher Education, 68(6), 599-623.

Tinto, V. (2012). Completing college: Rethinking institutional action, Chicago. The University of Chicago Press.

Thomas, M., A., S. \& Birchenough, A. (1996). Student withdrawal from higher education. Educational Management and Administration, 24(2), 207-221.

Tross, S. A., Harper, J. P., Osher, L. W., \& Kneidinger, L. M. (2000). Not just the usual cast of characteristics: Using personality to predict college performance and retention. Journal of College Student Development, 41(3), 323-334. 
O. Tzafea \& E. Sianou - Understanding Student Retention in Greece: The Impact of...

Yorke, M. (1999). Leaving early: Undergraduate non-completion in higher education. London \& Philadelphia: Palmer Press.

Yorke, M., \& Thomas, L. (2003). Improving the retention of students from lower socio-economic groups. Journal of Higher Education Policy and Management, 25(1), 63-74.

Yorke, M., \& Longden, B. (2004). Retention and student success in higher education. Society for Research into Higher Education: Open University Press. 